\title{
$1{ }^{\circ}$ CONAERG \\ CONGRESSO INTERNACIONAL DE ERGONOMIA APLICADA
}

\section{A ERGONOMIA DE CONCEPÇÃO COMO FATOR DIRETIVO EM PROJETOS DE CÂMERAS FOTOGRÁFICAS}

\author{
Júlio César Riccó Plácido da Silva (1); \\ José Carlos Plácido da Silva (2). \\ (1) Universidade de São Paulo - Faculdade de Arquitetura e Urbanismo (FAU), \\ Douturando. \\ e-mail: julioricco@usp.br \\ (2) Universidade Estadual Paulista - Faculdade de Artes, Arquitetura e Comunicação \\ (FAAC), Titular. \\ e-mail: placido@faac.unesp.br
}

\begin{abstract}
RESUMO
A presente pesquisa é fruto de uma reflexão profunda e fundamentada de como a ergonomia de concepção é importante e significativa na geração de produtos que tenham uma relação de melhor amigabilidade com o usuário. Nesse estudo o foco principal são os equipamentos fotográficos, indicando futuros parâmetros a serem observados quando da concepção de novos produtos relacionados às câmeras fotográficas.
\end{abstract}

\section{ABSTRACT}

The present inquiry is a result of a deep and substantiated reflection of as the conception ergonomics is important and significant in the products generation that have a relation of better friendliness relationship with the user. In this study the main focus are the photographic equipments, indicating parameters futures to be observed when of the conception of new products relating to the photographic cameras.

\section{INTRODUÇÃO}

Considerando a importância dos equipamentos fotográficos e levando em consideração sua crescente utilização tanto por profissionais como por amadores, o artigo direciona seus estudos no intuito de verificar e ressaltar a importância da ergonomia de concepção na execução de novos projetos, que objetivam aprimorar o desempenho no ato de fotografar, além de proporcionar o máximo de conforto, segurança, eficiência e qualidade para o registro fotográfico, assim como apresentar e analisar acessórios para a ferramenta. Sendo que esses acessórios vêm suprindo de forma satisfatória os problemas de pega e empunhadura, ao reduzir as exigências biomecânicas, auxiliando nos movimentos naturais do corpo humano e diminuindo os erros de projeto. 
O progresso projetual tem buscado manter o design tradicional das câmeras fotográficas, acrescentando apenas pequenas alterações em sua tipologia, seguindo linhas que tão somente buscam reduzir os aparelhos. Todavia, um dos destaques das tipologias construtivas do design é a ergonomia dos acessórios, especialmente quanto às pegas e empunhaduras. Esses elementos são absolutamente significativos para um bom design ergonômico, apesar de estarem sendo esquecidos devido aos avanços dos recursos eletrônicos e interfaces destinadas à redução do equipamento.

Assim, verifica-se a necessidade de maiores estudos sobre os equipamentos fotográficos, especialmente em relação às pegas e empunhaduras, a fim de que estas possam ser mais bem utilizadas, uma vez que, para a fotografia, executar a tarefa com exatidão é imprescindível. Quando do desenvolvimento dos projetos, deve-se estar atento às características funcionais das mãos, para que o equipamento também apresente melhor desempenho e o usuário possa realizar a tarefa com o mínimo de esforço possível, já que o trabalho de fotógrafos profissionais, por exemplo, não raro estende-se até 12 horas.

Em que pese a mão humana seja considerada um dos principais instrumentos do corpo humano destinados à manipulação, principalmente pela peculiar característica de possibilitar movimentos de preensão, associando força e destreza, as pesquisas realizadas no campo da ergonomia para pega/empunhadura de equipamentos fotográficos são reduzidas ou quase inexistentes. Assim, a pesquisa destaca a necessidade de investigações ininterruptas nessa área, devido à grande quantidade de câmeras no mercado e por se tratar de uma ferramenta que exige exatidão e precisão na execução da tarefa.

Com o desenvolvimento tecnológico, o tamanho das câmeras seguiu a tendência geral de miniaturização dos objetos. Assim, a fotografia, impulsionada pelas novas tecnologias, popularizou-se, amalgamando-se com outros equipamentos, como, por exemplo, o celular. Ocorre que os celulares, em geral, não têm o tamanho e formato adequados para a fotografia, uma vez que nesses aparelhos os dedos não aplicam a força de forma eficaz, pois parte dos músculos flexores ficam bastante encurtados e perdem sua capacidade de produzir tensão contrátil (SILVA; SILVA, 2013), durante processos repetitivos e por longos períodos de uso da ferramenta.

Aprimoramentos tecnológicos visam à reprodução fiel da realidade e por consequência programam a automatização do aparelho, o que acarreta diminuição da relação Homem x Máquina, tornando essa ferramenta um equipamento de simples operação, porém com poucas possibilidades de intervenção. Os projetos têm sido desenvolvidos nos últimos anos aparentemente de maneira satisfatória, no entanto, assim como ocorre com outros objetos que são desenvolvidos a partir de altas tecnologias, a usabilidade acaba não ocupando posição relevante no planejamento do produto.

A presente pesquisa, por conseguinte, pretende resgatar estudos já realizados e apresentar a importância da ergonomia no desenho de equipamentos fotográficos, sejam eles profissionais ou não, ressaltando que as mudanças de pega $\mathrm{e}$ empunhaduras introduzidas têm relação direta com o desempenho e a eficiência da ferramenta. Dessa maneira, objetiva-se destacar os acessórios, que estão suprindo de forma satisfatória os problemas apresentados de pega e empunhadura, buscando 
reduzir exigências biomecânicas, auxiliando nos movimentos naturais do corpo humano, e diminuir os erros de projeto.

O estudo foi delineado em quatro fases de estudo: a ergonomia de concepção, antropometria no projeto, biomecânica ocupacional e pega e empunhadura. Essas informações são de fundamental importância para compreender em profundidade o significado e a relevância que a ergonomia de concepção tem para o desenho de câmeras fotográficas, desenvolvendo pegas e empunhaduras que obedeçam às características funcionais das mãos e que contribuam, desta forma, para que se tenha um desempenho melhor de suas funções.

\section{ERGONOMIA DE CONCEPÇÃO}

Grande parte dos equipamentos fotográficos persiste em uma tendência de design universal, não comtemplando as necessidades específicas de cada usuário ou de grupos específicos. Grande parte dos equipamentos encontrados no mercado também não oferece interfaces adequadas ao seu manuseio, necessitando de avanços no campo ergonômico.

Para o desenvolvimento da ergonomia na concepção de equipamentos fotográficos é necessário compreender como os equipamentos são utilizados pelos profissionais. Esse é o ponto-chave para revelar como realmente o equipamento funciona e de como sofre interferência dos acessórios utilizados pelos indivíduos a fim de deixar a ferramenta adequada às suas condições de trabalho.

Grande parcela dos fotógrafos adquire acessórios para adaptar as câmeras às suas necessidades, principalmente ergonômicas. Alguns desses acessórios estão identificados abaixo, visando destacar que problemas de projetos existem e estão disponíveis no mercado.

A alça de mão (Hand Strap Grip - Figura 1) é necessária quando a empunhadura do equipamento não foi projetada para utilização da câmera por longos períodos de tempo, não permitindo também a preensão entre os dedos e a palma da mão. A alça, portanto, faz a adaptação da palma da mão ao equipamento, fixando o dorso da mão e ampliando o contato da mão com o corpo da câmera.

Figura 1. Hand Strap Grip for Canon

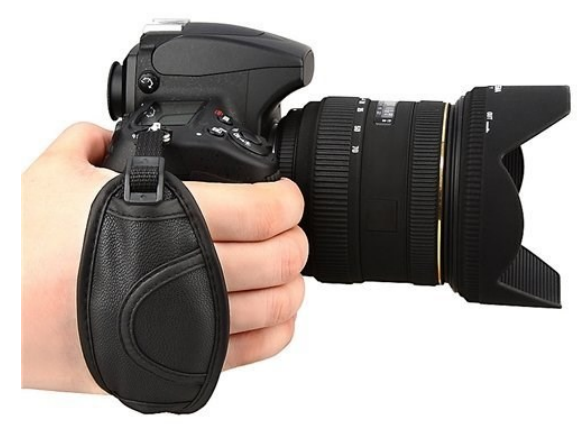


Fonte: <http://goo.gl/ptRRvO> - Acesso em 05 de julho de 2016.

Um dos acessórios que fazem parte integrante apenas de câmeras profissionais, também vendidos separadamente para melhorar a pega do equipamento, é o suporte para bateria (Battery Grip - Figura 2). O suporte aumenta a estabilidade, facilita o manuseio e proporciona maior conforto, principalmente na captura de imagens na vertical, além de solucionar problemas ergonômicos encontrados em alguns modelos de câmera que não possuem empunhadura. A empunhadura do equipamento deve ser um apoio confortável e deve também permitir a livre movimentação dos dedos a fim de reduzir a força de preensão exercida. Tal anteparo tem por finalidade, ainda, proteger o equipamento contra possíveis quedas e proporcionar maior firmeza na hora da captura (SILVA; SILVA, 2013).

Figura 2. Battery Grip

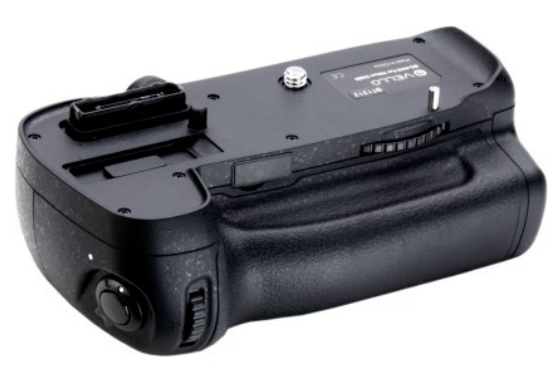

Fonte: <http://goo.gl/04Urp0> - Acesso em 30 de agosto de 2015.

Outro acessório que também pode ser adquirido separadamente, e que em grande parte dos modelos já vem disponível no próprio equipamento, é o visor de cristal líquido (LCD - Figura 3) reclinável. Ele serve para minimizar os efeitos da tensão no pescoço, além de permitir uma postura correta do usuário ao manusear o equipamento, evitando lesões nos músculos e na coluna. Esse acessório já vem inserido na maioria dos equipamentos proporcionando capturar ângulos e poses inusitadas. Todavia, com o consequente desuso do visor ocular (viewfinder), a distância entre o equipamento e o corpo tornou-se mais acentuada, principalmente para a função de vídeo, incorporada nas câmeras digitais de reflexos por uma lente (digital single-lens reflex câmera - DSLRs ou SLRs) e nas câmeras sem espelho de lentes intercambiáveis (mirrorless interchangeable lens câmera - MILC).

Figura 3. Visor de cristal líquido reclinável 


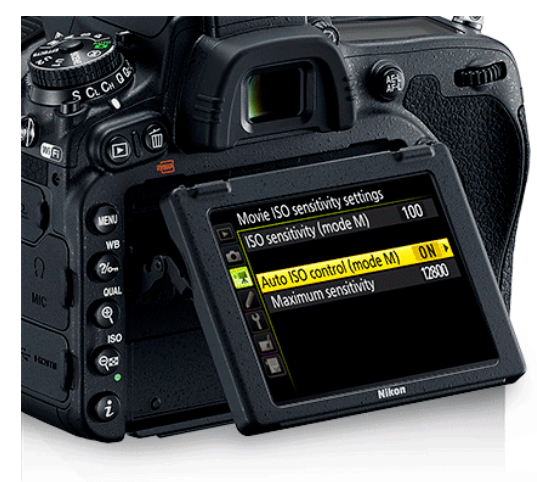

Fonte: <http://goo.gl/GFo1j4> - Acesso em 30 de agosto de 2015.

Outro acessório para câmeras de pequeno formato (mirrorless interchangeable lens câmera - MILC) é o suporte para o polegar (Thumb Up Hot Shoe Camera Grip Figura 4), que surgiu devido à falta de espaço para apoiar o polegar em uma superfície rígida, causando grande dificuldade de segurar a câmera.

Figura 4. Thumb up hot shoe câmera grip

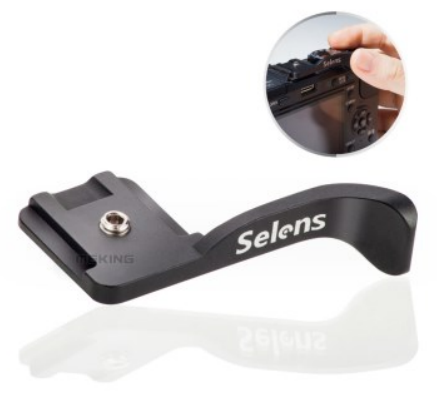

Fonte: <http://goo.gl/pS6Gk9> - Acesso em 05 de julho de 2016.

O uso da tira de pescoço, quando o fotógrafo não está utilizando o equipamento, acaba causando um estresse adicional em decorrência do peso do equipamento fotográfico, o que força a cabeça para baixo, provocando dores no pescoço e nas costas assim. Para minimizar esses efeitos se faz necessário o uso de acessórios (o cinto duplo de ombro ou o cinto de cintura - Figura 5 e 6) que possibilitem ao usuário ficar com as mãos livres, e distribuir o peso da câmera pelo corpo, fazendo com que os músculos intrínsecos e os músculos extrínsecos relaxem.

Figura 5. Cinto duplo de ombro 


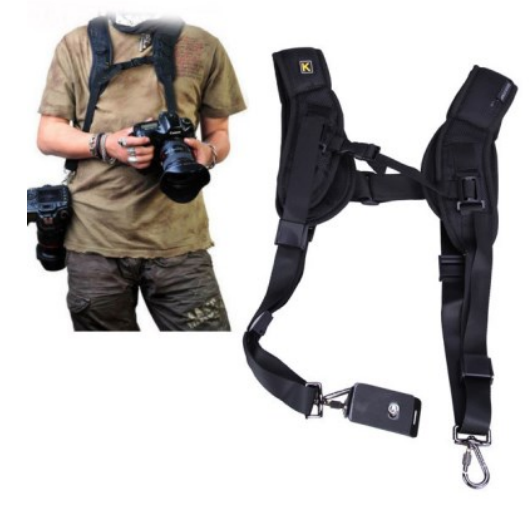

Fonte: <http://goo.gl/MBK0gP > - Acesso em 05 de julho de 2016.

Figura 6. Cinto de cintura

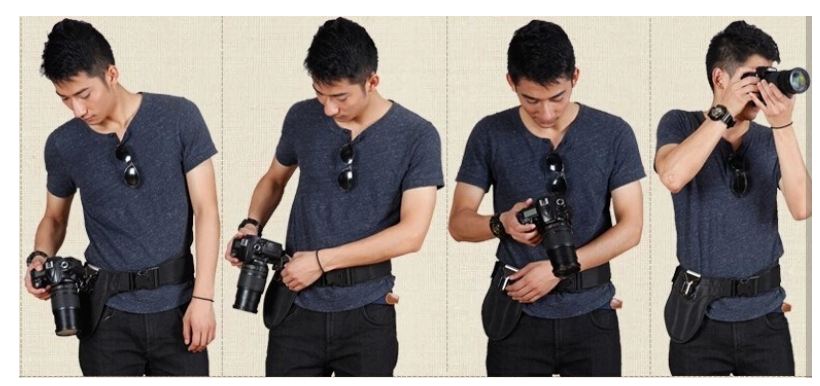

Fonte: <http://goo.gl/uwvRbY> - Acesso em 05 de julho de 2016.

Ferramentas manuais, como o equipamento fotográfico, não devem exceder $2 \mathrm{~kg}$. Toda via, alguns equipamentos, que possuem lentes de longo alcance, comumente ultrapassam essa recomendação, quando se faz necessária a utilização de monopes (Figura 7) para aliviar o peso do instrumento.

Figura 7. Monope

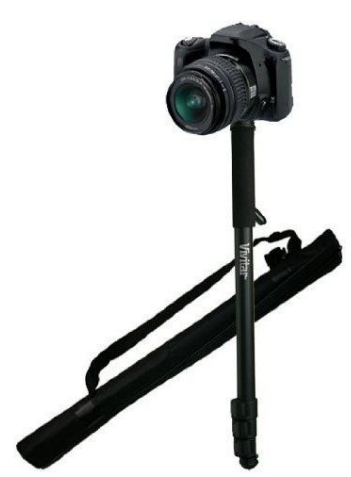


Fonte: <http://goo.gl/Au7UKp> - Acesso em 30 de agosto de 2015.

É evidente que a existência de uma grande quantidade de acessórios que visam melhorar a usabilidade do equipamento demonstra como o desenho e a redução do tamanho da câmera estão sendo projetados de forma inadequada, não suprindo as necessidades do profissional, que não raro ultrapassam as doze horas de trabalho. Segundo Dul e Weerdmeester (1995), o usuário deve escolher uma câmera que se adapte às tarefa e à sua postura, de modo que as articulações possam ser mantidas em uma posição neutra. É importante enfatizar que os projetistas, ao desenvolverem novos projetos de câmeras devem levar em consideração as características individuais, distinguindo os possíveis usuários e empregos do equipamento.

\section{ANTROPOMETRIA NO PROJETO}

Um dos aspectos ligados à ergonomia de concepção é a utilização da antropometria no projeto, uma vez que no projeto é necessário definir para qual tipo biofísico e para quais faixas da população o produto é feito (CARPES JR., 2014).

No caso de câmeras fotográficas, todos os modelos existentes são padronizados, não atendendo a um tipo biofísico, nem às faixas da população. Mesmo que o equipamento siga características anatômicas em sua pega, elas devem ter aderência adequada para a função e o tamanho, levando em conta as medidas antropométricas das mãos (RIO; PIRES, 2001).

Acredita-se que os parâmetros antropométricos da mão são necessários para definir tamanhos precisos de empunhadura, gerando uma média mais precisa dentre os usuários de cada país. O tamanho da mão não exerce influência na força de preensão. No entanto, é necessário avaliar três valores antropométricos relacionados à mão: extensão, comprimento dos dedos e perímetro da mão.

Grant, Habes e Steward (1992) avaliaram a influência do diâmetro das pegas na redução do esforço manual. Por meio de um estudo laboratorial, os autores calcularam, com sensores eletromiográficos de superfície, a tensão gerada pelo esforço dos músculos da mão. Os referidos autores asseguram que é praticamente impossível indicar um diâmetro ideal único, que seja adequado a todos os usuários em todas as situações.

Seguindo esses preceitos da ergonomia, Luigi Colani e Giorgetto Giugiaro destacamse por seus estudos pioneiros em relação ao desenho de máquinas fotográficas com empunhaduras mais adequadas à mão humana.

O desenho do modelo T90, da marca Canon, de autoria de Luigi Colani, lançada em 1986, introduziu um novo padrão de design no setor de equipamentos fotográficos profissionais, servindo de base para a criação de equipamentos com maior usabilidade em relação à empunhadura, devido ao seu alto nível de interface com o usuário. 
Giugiaro desenvolveu seu primeiro projeto para a empresa Nikon em 1979, mas apenas em 1981 desenvolve a Nikon F3, onde todas as pesquisas foram voltadas aos aspectos ergonômicos, introduzindo soluções úteis para melhorar a aderência e a capacidade de manobra da ferramenta nas mais diversas situações. A inclinação do bloco do motor favorece a aderência da palma da mão.

\section{BIOMECÂNICA OCUPACIONAL - MÃO HUMANA}

Tanto a antropometria, como a biomecânica ocupacional, devem ser consideradas no projeto de produto. A biomecânica ocupacional estabelece a relação entre o trabalho e o homem, no tocante aos movimentos de músculos e ossos envolvidos e suas consequências. Isso contempla a questão das posturas corporais e a aplicação de forças no trabalho (IIDA, 2005), definindo-se dois tipos de trabalhos musculares: trabalho estático e trabalho dinâmico.

Como o fotógrafo trabalha em pé, esse esforço exige muito trabalho estático da musculatura envolvida, pois exige contração contínua dos músculos a fim de manter uma determinada posição. Para realizar um simples movimento, diversos músculos, ligamentos e articulações do corpo são acionados. Assim, a maioria das atividades ocupacionais e cotidianas é realizada por meio da intervenção humana, sendo que, nesse caso, a capacidade de um indivíduo desempenhar o trabalho mecânico é produzida por sua capacidade de exercer força muscular (MITAL; KUMAR, 1998).

Estudos sobre membros superiores não são recentes, todavia vêm sendo mais bem investigados conforme a ampliação dos materiais empregados nos produtos. Na natureza não existe nada que seja comparável à mão humana (NAPIER, 1985), sendo mesmo uma ferramenta ímpar, capaz de realizar inúmeras ações devido à sua função essencial: a preensão (KAPANDJI, 2007). Assim, graças à mobilidade dos dedos, especificamente do dedo em oposição aos demais, é possível conseguir uma grande variedade de manejos, com variações de velocidade, precisão e força dos movimentos.

Segundo Carpes Jr. (2014), para a aplicação de força na operação de um equipamento, devem ser considerados os seguintes critérios:

- Precisão: obtém-se maior precisão com as pontas dos dedos.

- Ritmo: os movimentos devem ser suaves, curvos e rítmicos, visto que movimentos retos são difíceis e imprecisos e exigem complexas integrações entre as articulações.

- O posicionamento preciso de algum objeto ou controle é difícil e demorado.

Tem-se que a ferramenta fotográfica é uma extensão das mãos. Compreendê-la no que se refere à biomecânica da mão e às forças a serem aplicadas em sua empunhadura, identificando a realidade de uso pelo profissional, é de fundamental importância, tanto no que se refere a um aperfeiçoamento no seu desempenho, em conformidade com as capacidades físicas do ser humano, quanto na prevenção de possíveis lesões ocasionadas por seu mau desenvolvimento e pelas condições que implicam no bom uso da empunhadura (SILVA; SILVA, 2015). 
Se a câmera é muito pequena, os dedos não podem aplicar força de forma eficaz, em parte porque os músculos flexores ficam bastante encurtados, perdendo sua capacidade de produção de tensão contrátil. Esta limitação do desempenho muscular aplica-se especialmente quando o indivíduo tenta segurar um objeto pequeno com força ou um cabo de ferramenta com o punho fletido, o que encurta os músculos flexores dos dedos (CHAFFIN et al., 2001).

\section{PEGA E EMPUNHADURA}

As ferramentas são na verdade a extensão das mãos. Compreendê-las no que se refere às pegas e às forças a serem aplicadas é de fundamental importância para os profissionais que as projetam. A ferramenta tem sido modificada ao longo dos anos e, aparentemente, de maneira satisfatória, no entanto existem novos esforços e diretrizes na tentativa de se apresentar desenhos e projetos não convencionais que possibilitem melhor usabilidade para o consumidor, além de oferecer maior facilidade operacional e conforto na execução da tarefa.

Quando o trabalho é predominantemente de precisão, as pegas devem facilitar o uso da parte radial das mãos. Entretanto, a redução das dimensões dos equipamentos fotográficos e seus botões têm causado uma série de dificuldades no seu manejo, conforme mencionado anteriormente, razão pela é necessária a criação de diversos acessórios para suprir tais problemas, que comprometem a usabilidade, quando a agilidade e a precisão são imprescindíveis à realização da tarefa.

Para Dul e Weerdmeester (1995) pega é a parte da ferramenta ou equipamento segurado pelas mãos. A forma e a localização da mesma devem possibilitar uma boa postura para as mãos e braços. O desenho adequado do manejo tem uma grande influência no desempenho do sistema homem - máquina (IIDA, 2005). A pega deve ser um pouco convexa a fim de aumentar o seu contato com as mãos. Não se recomenda o uso de pegas anatômicas ou antropomorfas (com sulcos para encaixe dos dedos), pois os dedos tendem a ficar apertados, dificultando as mudanças de posição. Para não torcer o punho o ideal são as ferramentas com empunhaduras orgânicas, pois permitem conservar o punho reto (DUL; WEERDMEESTER, 1995).

Portanto, diversos fabricantes empregam a pega convexa, visando aumentar a superfície de contato do equipamento. Outros, analisando o peso da câmera e o tempo durante o qual é utilizada, ainda optam pela introdução do sulco para encaixe do dedo médio.

O equipamento fotográfico é um artefato que tem suas funções acionadas exclusivamente pelas mãos, mais precisamente pelas pontas dos dedos, motivo pelo qual deve ser estudada a luz dos conhecimentos sobre manejo, pega e empunhadura. Isso ganha maior importância no momento em que seu tamanho tem sido gradativamente diminuído em função da tendência à miniaturização dos objetos detentores de alta tecnologia. A redução das dimensões do equipamento fotográfico tem causado uma série de dificuldade no seu manejo e consequente comprometimento de sua usabilidade. O que ocorre devido à força de preensão e o estresse causado nos tendões dos músculos flexores dos dedos, que variam de acordo com o tamanho do objeto a ser pego. 
Sendo a ferramenta muito pequena, os dedos não podem aplicar força de forma eficaz, pois em parte os músculos flexores ficam bastante encurtados, perdendo sua capacidade de produção de tensão contrátil. Tal redução no design da ferramenta deve-se aos desenhos com linhas retas para que ocupe cada vez menos espaço e possa ser transportado com facilidade a qualquer lugar. No entanto, a tendência de redução das câmeras tem aumentado a tensão nas mãos, uma vez que seguem movimentos contrários aos naturais do corpo humano, dificultando a realização de movimentos retilíneos. Apesar de ser adequado para segurar pequenos objetos no centro da palma da mão, não é preparado para resistir à aplicação direta de força.

lida (2005) salienta que a concentração de tensões na mão pode ser reduzida melhorando o desenho da pega, aumentando seu diâmetro, eliminando superfícies angulosas e substituindo as superfícies lisas por outras, rugosas ou emborrachadas. As empunhaduras emborrachadas distribuem a força pelos dedos e palma da mão, evitando o estresse em áreas sensíveis.

De acordo com lida (2005), existe um grande número de formas intermediárias entre o manejo geométrico e o manejo endomorfo, procurando combinar as vantagens de cada uma delas, ou seja, suavizando a rigidez da pega antropomorfa, mas aumentando a área de contato da pega geométrica. Por isso o desenho da máquina fotográfica necessita se valer dos benefícios tanto do manejo geométrico como do endomorfo, não se prendendo às características de apenas um deles.

No entanto, é um equipamento que exige precisão e velocidade no instante da captura da imagem, o que é característico do manejo fino. lida (2005) salienta que o manejo fino é executado com a ponta dos dedos. Os movimentos são transmitidos principalmente pelos dedos, enquanto a palma da mão e o punho permanecem relativamente estáticos. Este tipo de manejo caracteriza-se pela grande precisão e velocidade, com pequena força transmitida nos movimentos.

Contudo o botão que aciona o equipamento para realizar a captura deve ser de alta sensibilidade devido a um ajuste fino preciso e importante. É fundamental que a sensibilidade do botão disparador possa ser ajustada conforme a sensibilidade mecânica do usuário, visto que essa sensibilidade varia de pessoa para pessoa. Porém, até o momento, essa interferência não foi inserida nos equipamentos.

Deve-se observar que objetos empregados como dispositivos de aumento de comprimento da força e/ou modificação da direção da mão ou do braço devem ser projetados de forma que durante o uso sigam a orientação da longa linha central ou que o centro de gravidade do objeto fique alinhado com a linha central da mão e do braço.

Grande parte das câmeras não distribui seu peso e gravidade centrais alinhando-se à linha central da mão, devido à troca de objetivas que são de formatos e pesos diferentes. Assim, a força de preensão varia significativamente com a largura da pega, medida no centro da mão. $E$ o formato da seção transversa de um objeto, assim como a dimensão, afeta o desempenho de força de preensão (CHAFFIM, ANDERSON E MARTIN, 2001). Portanto, as câmeras não devem ser tão pequenas a ponto de comprometer o desempenho das mãos. Pegas mais robustas, visíveis em câmeras não populares, facilitam o uso e aumentam o conforto do usuário. 
Para que as câmeras fotográficas apresentem mais usabilidade é necessário que se apliquem os estudos sobre pega e empunhadura já existentes e/ou que gerem diretrizes para futuros estudos. Sendo que a empunhadura do equipamento deve ser um apoio confortável, onde exista espaço livre para a movimentação dos dedos a fim de reduzir a força de preensão e proporcionar um bom apoio. Tal anteparo deve também se constituir como uma proteção do equipamento contra quedas.

Napier (1985) ressalta a importância dos estudos e do conhecimento dos termos que se aplicam fundamentalmente ao design da empunhadura das ferramentas. $O$ desenho deve sempre ser ditado pela natureza da operação envolvida. No entanto, o que se observa com frequência é que a capacidade inventiva se concentra muito mais na parte operacional, olvidando-se das questões que envolvem o punho e/ou a empunhadura. $\mathrm{O}$ autor destaca a capacidade que a mão humana tem de ser altamente adaptável, podendo, assim, obter uma preensão firme sobre quase todos os tipos e modelos de pegas. Entretanto, para que a ferramenta tenha máxima eficiência, o punho deve sempre ser desenhado observando-se sua função específica (SILVA; SILVA, 2015).

Recomenda-se evitar cantos agudos e ressaltos, preservar a pele e toda a estrutura da mão humana de possíveis impactos e temperaturas elevadas, já que algumas câmeras, quando utilizadas por longos períodos, aquecem demasiadamente (na grande maioria dos equipamentos a bateria fica alocada na empunhadura), transferindo o calor para as mãos e provocando suor. Esse estado dificulta o manuseio e a capacidade real de uso do produto, em especial quando as pegas são produzidas em material que não tenham tratamento antitranspirante (SILVA; SILVA, 2015).

\section{CONSIDERAÇÕES FINAIS}

Da pesquisa realizada, é clarividente que existem graves problemas nos projetos de equipamentos fotográficos e que é necessário que projetistas observem os conceitos da ergonomia de concepção no desenvolvimento de projetos, principalmente aqueles com vistas à pega e a empunhadura. Outro ponto evidente é a existência de uma grande quantidade de acessórios que melhoram a usabilidade do equipamento, demonstrando como o design e a redução do tamanho das câmeras interferem negativamente em sua utilização pelos usuários profissionais.

Para o prosseguimento da pesquisa, que objetiva subsidiar futuras investigações, um ponto a destacar é o da relação de força exercida sobre as empunhaduras. Para tanto será preciso empregar um dinamômetro, em inúmeros padrões de empunhaduras préselecionadas anteriormente. Os dados serão digitalizados e construídos os modelos por meio da prototipagem rápida, observando a escala real a fim de verificar qual é a média de diâmetro presente nesses equipamentos profissionais e assim propor novos parâmetros para pegas que estejam adequadas às medidas antropométricas das mãos estudadas.

A pesquisa tem também a intenção de contribuir para os novos estudos relacionados à área da ergonomia de concepção e assim subsidiar novos parâmetros para projetos de câmeras fotográficas que possuam uma melhor relação de usabilidade quando do ato de fotografar. 


\section{REFERÊNCIAS BIBLIOGRÁFICAS}

CARPES JR, Widomar P. Introdução ao Projeto de Produtos. Bookman Editora, 2014.

CHAFFIN, D. B.; ANDERSSON, G. B. J.; MARTIN, B. J. Biomecânica ocupacional. Belo Horizonte: Ergo Editora, 2001. 579 p.

DUL, J.; WEERDMEESTER, B. Ergonomia Prática. São Paulo: Ed. Edgard Blüncher, 1995.

GRANT, Katharyn A.; HABES, Daniel J.; STEWARD, Libby L. An analysis of handle designs for reducing manual effort: the influence of grip diameter. International Journal of Industrial Ergonomics, v. 10, n. 3, p. 199-206, 1992.

IIDA, I. Ergonomia Projeto e Produção. São Paulo: Ed. Edgard Blüncher, 2005.

KAPANDJI, A. I. Fisiologia articular: membro superior. $6^{a}$. ed. Rio de Janeiro: Guanabara Koogan, v. 1, 2007.

MITAL, A.; KUMAR, S. Human muscle strength definitions, measurement, and usage: Part I - Guidelines for the practitioner. International Journal of Industrial Ergonomics, 22, 1998. p. 101-121.

NAPIER, J. The prehensile movements of the human hand. Journal of Bone and Joint Surgery, 38B, n. 04, 1956. p. 902-913.

RIO, R. P., PIRES, L. Ergonomia: Fundamentos da prática ergonômica. São Paulo: LTr. 2001.

SILVA, J. C. R. P.; SILVA, J. C. P. Empunhadura: sua influência nos processos e procedimentos artemidiáticos do fotógrafo. In: $13^{\circ}$ Congresso Internacional de Ergonomia e Usabilidade de Interfaces, Juiz de Fora / MG. Anais do $13^{\circ}$ Ergodesign e $13^{\circ}$ USIHC: $13^{\circ}$ Congresso Internacional de Ergonomia e Usabilidade de Interfaces, v. 1. p. 1-100, 2013.

SILVA, J. C. R. P.; SILVA, J. C. P. A importância da ergonomia para a concepção de equipamentos fotográficos profissionais. In: ETD'15 - 4o Ergotrip Design, 2015, Aveiro. ETD'15 - 4o Ergotrip Design, Aveiro: livro de resumos / coord. Álvaro Sousa, Francisco Providência, Cátia Pereira. Aveiro: UA Editora, 2015. v. 1. p. 1-52. 